\title{
Cisto ósseo simples do acrômio: Relato de caso*
}

\section{A Simple Bone Cyst of the Acromion: Case Report}

\author{
Recep Öztürk ${ }^{1 \odot}$ \\ Emin Kürşat Bulut ${ }^{1 \oplus}$
}

\author{
Ömer Faruk Ateș ${ }^{2}$ Bedii Şafak Güngör ${ }^{1 \odot}$
}

Endereço para correspondência Recep Öztürk, MD, Dr. Abdurrahman Yurtaslan Ankara Oncology Training and Research Hospital, Demetevler Mahallesi, Vatan Cad., Yenimahalle, Ankara, 06200, Turquia (e-mail: ozturk_recep@windowslive.com).

\section{Resumo \\ Palavras-chave \\ - cistos ósseos \\ - acrômio \\ - escápula}

Cistos ósseos simples são raros na escápula, e, pelo que sabemos, não foram relatados no acrômio. Aqui, apresentamos uma paciente do sexo feminino, de 24 anos, submetida com sucesso ao tratamento composto por curetagem e xenoenxerto. Não foram observados achados de recidiva no acompanhamento pós-operatório de seis meses, quando a paciente apresentou amplitude total de movimento e foi capaz de realizar todas as atividades rotineiras de maneira satisfatória.

Simple bone cysts rarely occur in the scapula, and, to our knowledge, they have not been reported in the acromion. In the present report, we present the case of a 24-yearold female patient who was successfully treated by curettage and grafting using xenografting. No recurrence findings were observed during the follow-up six months postoperatively, the patient had recovered full range of motion, and she was able to perform all routine activities satisfactorily.

\section{Introdução}

Os cistos ósseos unilaterais (COUs), também chamados cistos ósseos simples, são lesões benignas preenchidas por fluido nas metáfises de ossos longos. ${ }^{1}$ Em radiografias simples, são lesões líticas de contornos bem definidos, e a parede cística é recoberta por uma membrana fibrosa; seu interior contém um fluido seroso amarelo. ${ }^{2} \mathrm{~A}$ lesão tem etiologia desconhecida, e é mais observada entre 5 e 15 anos de idade. ${ }^{3}$ Embora tenham sido relatados em todos os ossos, esses cistos são

\footnotetext{
Estudo realizado no Departamento de Ortopedia, Dr. Abdurrahman Yurtaslan Ankara Oncology Training And Research Hospital, Ancara, Turquia.
}

recebido

19 de Março de 2020

aceito

01 de Junho de 2020

Publicado online

Setembro 22, 2020 bastante comuns na porção proximal do úmero e do fêmur. $^{4-6}$

O diagnóstico diferencial radiológico de uma lesão cística escapular em adolescentes inclui displasia fibrosa, cisto ósseo aneurismático, granuloma eosinofílico, osteoblastoma e infecção. ${ }^{7,8}$

Não há uma abordagem terapêutica padrão. Além do acompanhamento sem tratamento, muitas modalidades terapêuticas foram descritas, como a injeção local de corticosteroides, a realização de múltiplos orifícios, e a curetagem com colocação de enxerto. ${ }^{6,7}$

Relatamos aqui um caso de cisto ósseo simples localizado no acrômio. Não encontramos na literatura nenhum outro caso de lesão radiotransparente sintomática localizada no

(c) 2020. Sociedade Brasileira de Ortopedia e Traumatologia. All rights reserved.

This is an open access article published by Thieme under the terms of the Creative Commons Attribution-NonDerivative-NonCommercial-License, permitting copying and reproduction so long as the original work is given appropriate credit. Contents may not be used for commercial purposes, or adapted, remixed, transformed or built upon. (https://creativecommons.org/ licenses/by-nc-nd/4.0/)

Thieme Revinter Publicações Ltda., Rua do Matoso 170, Rio de Janeiro, RJ, CEP 20270-135, Brazil 


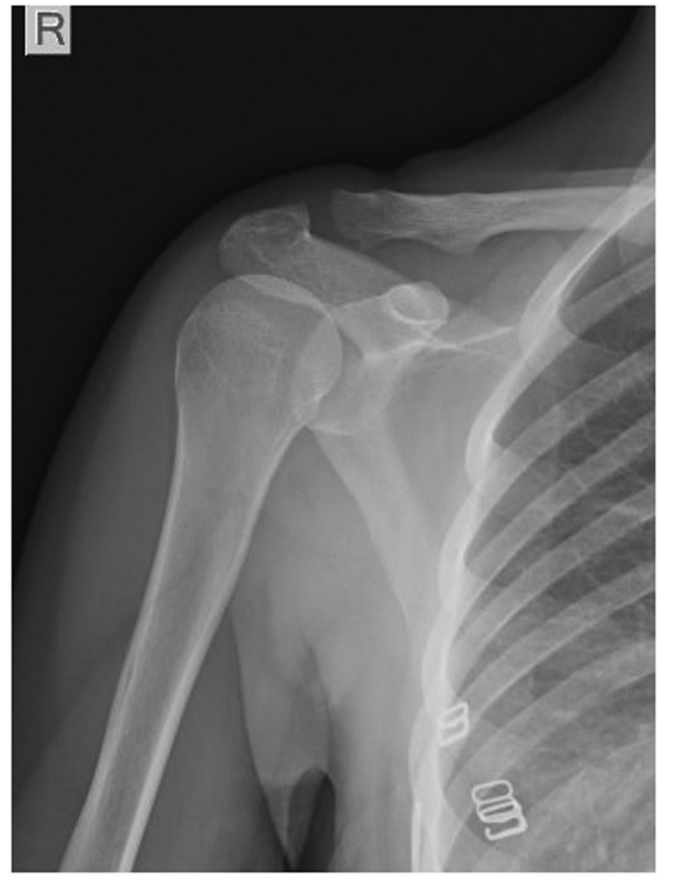

Fig. 1 Radiografia anteroposterior do ombro direito, mostrando uma lesão lítica minimamente esclerótica, com contornos bem definidos, sem expansão até o acrômio.
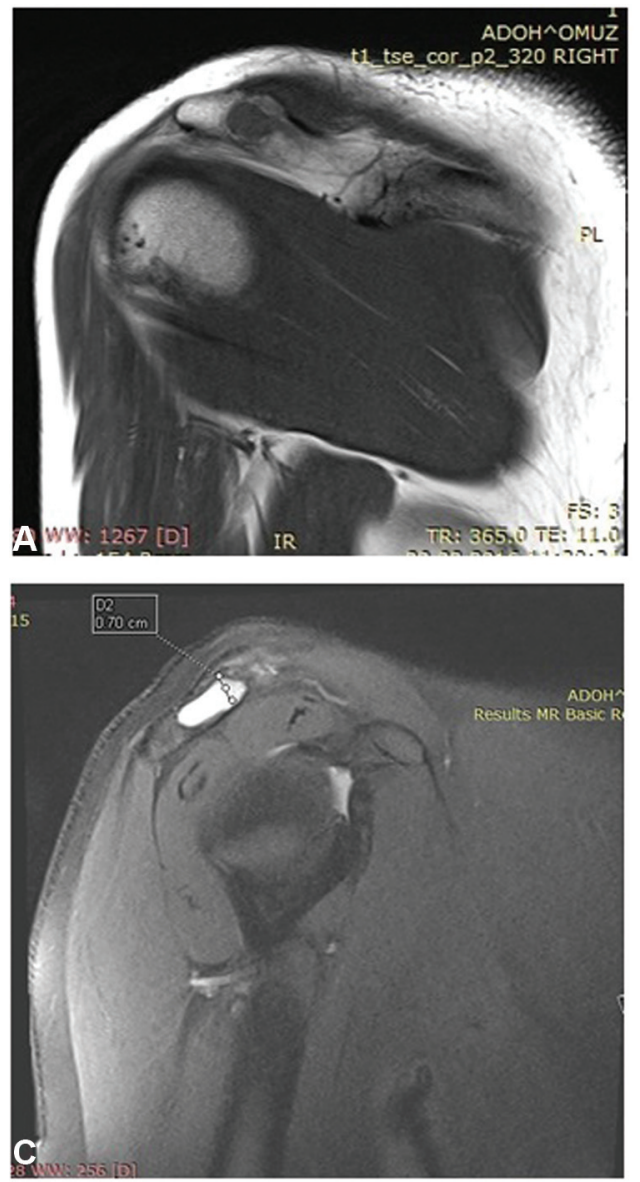

acrômio. O tratamento de nossa paciente, por curetagem e enxerto, foi realizado com sucesso.

\section{Relato de Caso}

Paciente do sexo feminino, de 24 anos de idade, compareceu ao nosso ambulatório de ortopedia com dor na porção lateral do ombro direito. A paciente relatou dor ocasional por cerca de um ano, mas com exacerbação recente. Edla não tinha histórico de trauma ou lesão por movimentos repetitivos. Não havia doença sistêmica. No exame físico, a paciente não apresentava edema ou hiperemia na lateral do ombro. A dor era associada à limitação do movimento do ombro direito. $A$ palpação do acrômio anterior causou dor. A paciente foi questionada sobre o uso dos dados referentes ao caso em publicação, e deu seu consentimento.

A radiografia simples em dois planos do ombro direito revelou uma lesão lítica com contornos bem definidos, margens escleróticas mínimas, e zona de transição estreita com lesão benigna, sem expansão até o acrômio. À ressonância magnética, as imagens ponderadas em T2 com supressão de gordura mostraram uma lesão cística não suprimida, hipointensa e homogênea, de intensidade igual
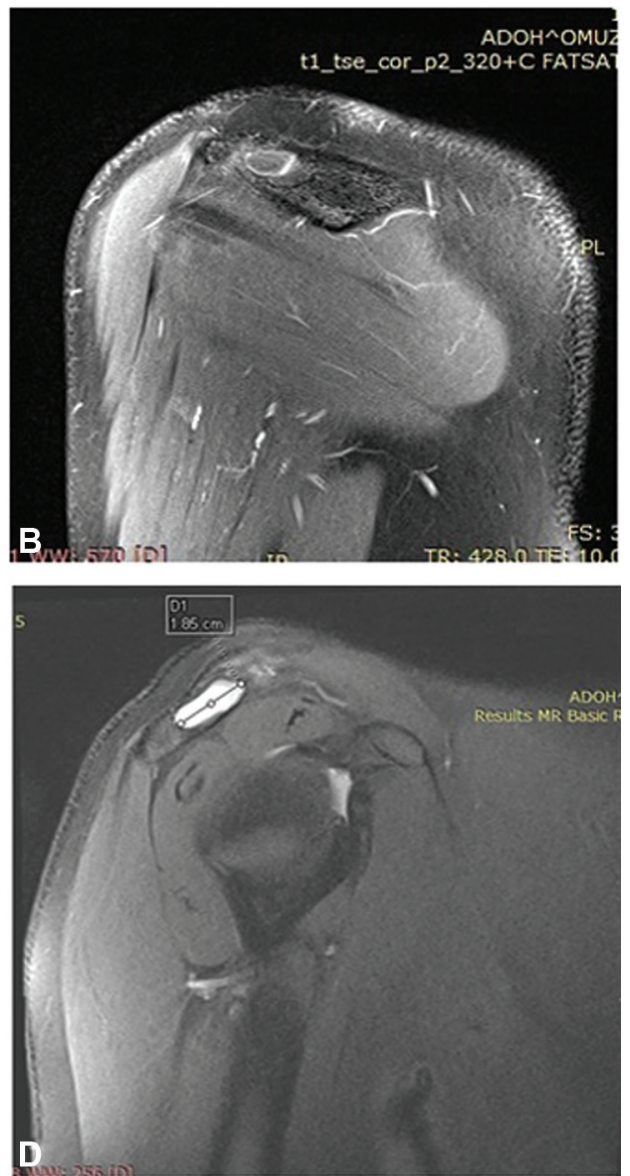

Fig. 2 (A) Imagem coronal de ressonância magnética ponderada em T1 do ombro direito, realizada antes da cirurgia, mostrando uma lesão hipointensa homogênea com contornos bem definidos, sem expansão até o acrômio. (B) Imagem coronal de ressonância magnética ponderada em T1 após a administração de contraste, com realce delgado periférico, mas ausência do material no centro da lesão. (C-D) Imagem coronal de ressonância magnética ponderada em T2 com supressão de gordura, realizada antes da cirurgia, mostrando uma lesão hiperintensa homogênea com contornos bem definidos, e uma fina parede esclerótica no acrômio. 


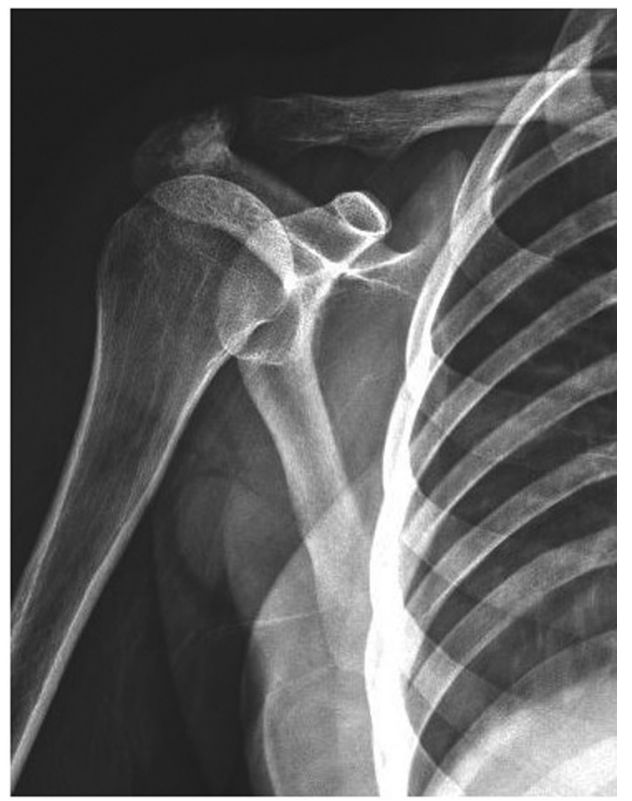

Fig. 3 Radiografia anteroposterior do ombro direito, mostrando as alterações pós-operatórias no acrômio, a ausência de lesão lítica, e áreas densas, com contornos irregulares, relacionadas ao material de enxerto. à do fluido; em imagens ponderadas em T1 após a injeção de contraste, havia um ligeiro realce na parede, mas não na região central ou nos septos da lesão (- Figuras 1 e 2 ).

A biópsia incisional foi planejada. À avaliação intraoperatória, um corte congelado foi obtido porque os achados macroscópicos sugeriam uma lesão cística benigna, assim como as radiografias, que indicavam um cisto ósseo simples; assim, a curetagem da cavidade com o uso de equipamento de alta velocidade em sua parede foi realizada na mesma sessão. A lesão recebeu um xenoenxerto de $10 \mathrm{~cm}^{3}$ (-Figura 3). 0 material coletado à curetagem foi enviado para exame histopatológico, que confirmou o diagnóstico de cisto ósseo simples.

Exercícios de amplitude de movimento ativo do ombro foram iniciados na terceira semana pós-operatória, e a paciente apresentou amplitude total de movimento sem dor. Não houve recidiva na ressonância magnética e na radiografia simples realizadas no sexto mês pós-operatório (-Figura 4). Outras complicações ou dor não foram observadas durante os seis meses de acompanhamento. A paciente realizou todas as atividades rotineiras de forma satisfatória (-Figura 5).
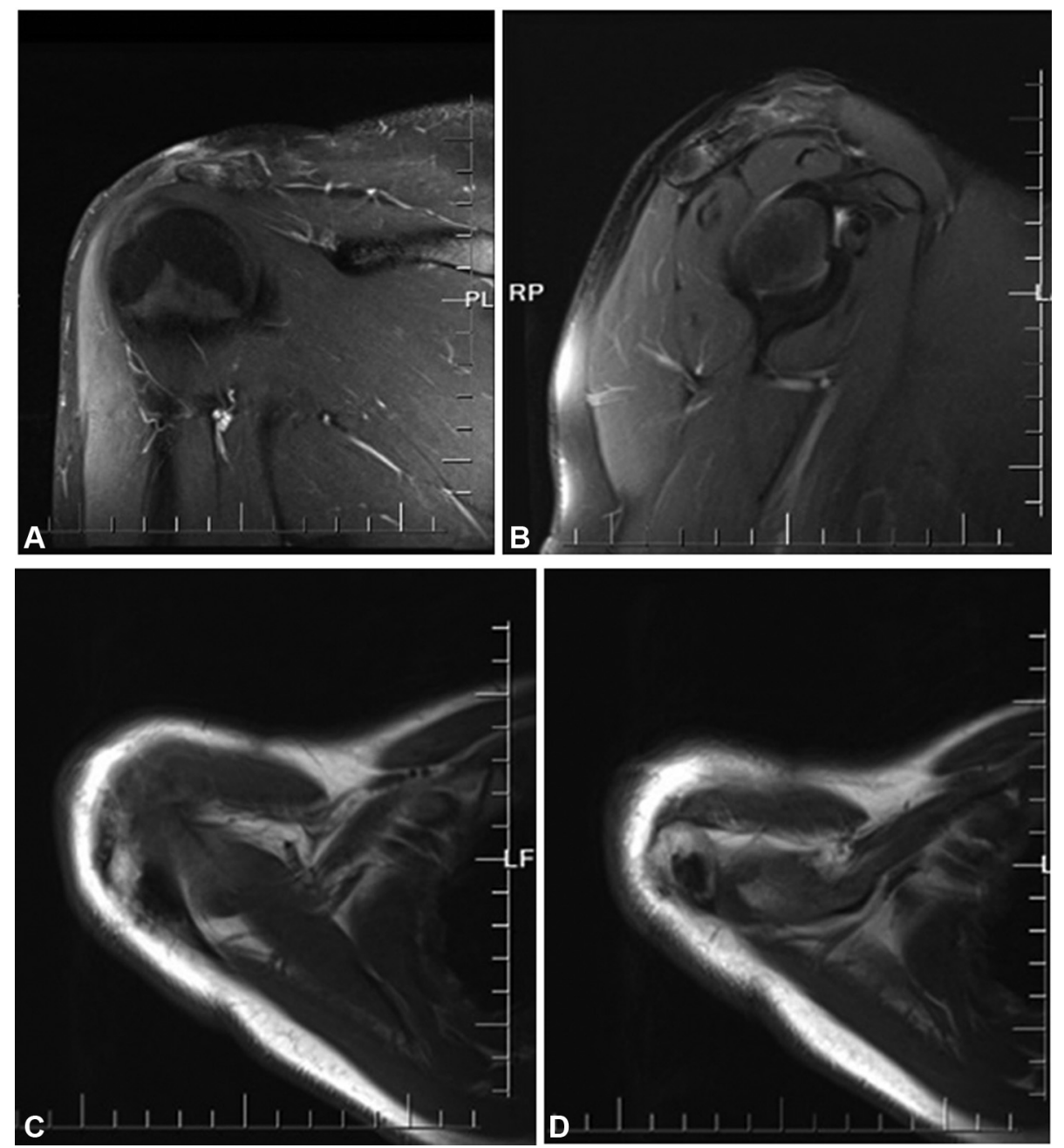

Fig. 4 (A-D) Imagens de ressonância magnética no sexto mês pós-operatório: imagens axiais ponderadas em T1 mostrando uma área de ausência parcial de sinal hipointenso e heterogêneo relacionada às alterações pós-operatórias no acrômio. Imagens coronal e sagital ponderadas em T2 com supressão de gordura, mostrando o tecido de granulação pós-operatório, esclerose, e uma imagem hiperintensa heterogênea de bordas irregulares secundária ao material cirúrgico de enxerto. 

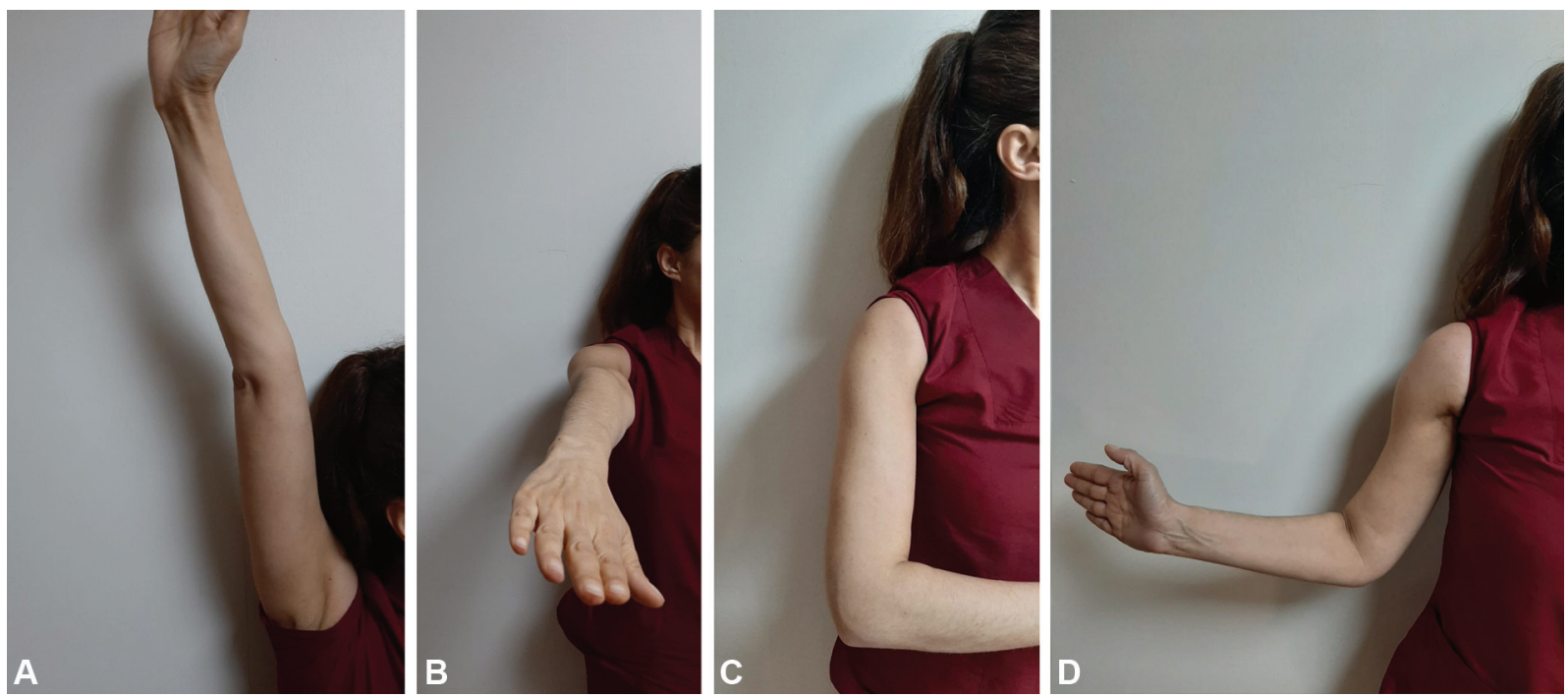

Fig. 5 (A-D) As fotografias clínicas mostram a amplitude total de movimento do ombro no final do período de acompanhamento.

\section{Discussão}

Os tumores da escápula são raros e frequentemente malignos. As lesões benignas e malignas que podem acometer a escápula tendem a ser observadas na infância. ${ }^{7,9}$ Indivíduos do sexo masculino são duas vezes mais afetados do que pacientes do sexo feminino. ${ }^{1}$ Diferentemente de todos esses sintomas, nosso caso, um tumor benigno em mulher adulta, é raro.

Os cistos ósseos simples foram descritos pela primeira vez por Virchow em $1876 .{ }^{10}$ A maioria dos cistos ósseos simples é observada na infância e definida como uma lesão do desenvolvimento/reativa. Sua etiologia é desconhecida. ${ }^{3,6}$

Os cistos ósseos simples geralmente ocorrem na metáfise de ossos longos, e têm predileção pela porção proximal do úmero e do fêmur. Em pacientes de idade mais avançada, o ílio e o calcâneo também são regiões em que esses cistos são detectados com frequência. ${ }^{6} \mathrm{O}$ acometimento da escápula é pouco frequente. Em nosso caso, a lesão estava localizada no acrômio.

Os pacientes com cistos ósseos simples tendem a apresentar fratura patológica ou dor branda. ${ }^{11}$

De acordo com os relatos de caso na literatura, ${ }^{12-15}$ o acometimento do acrômio por tumores benignos e malignos é raro. Outros casos, como de cisto ósseo aneurismático, tumores de células gigantes, condroblastoma e mieloma múltiplo, foram descritos no passado. ${ }^{12-15}$

Ainda não há consenso sobre a necessidade de tratamento (uma vez que a resolução pode ser espontânea) ou definição da terapia mais adequada para os cistos ósseos simples. ${ }^{11} \mathrm{O}$ principal objetivo do tratamento é a prevenção de fraturas patológicas, a erradicação do cisto, e o alívio da dor. Injeções locais de corticosteroides, transplante autólogo de medula óssea ou injeções de matriz óssea desmineralizada, autoaloenxertos de osso cortical-esponjoso, e muitos outros procedimentos foram descritos na literatura. ${ }^{6,7,10}$

Não existem princípios definidos sobre a forma de tratamento dos cistos ósseos simples, e cada método terapêutico apresenta taxas de sucesso e complicações específicas. ${ }^{11} \mathrm{Em}$ nosso caso, as indicações para a cirurgia foram os achados radiográficos condizentes com lesão cística no acrômio, e o histórico clínico relacionado à lesão.

Pelo que sabemos, nenhum outro cisto ósseo simples do acrômio foi relatado na literatura.

Conflito de Interesses

Os autores declaram não haver conflito de interesses.

\section{Referências}

1 Campanacci M, Enneking WF. Bone and soft tissue tumors. 2nd ed. New York: Springer Verlag; 1999:791-811

2 Tey IK, Mahadev A, Lim KB, Lee EH, Nathan SS. Active unicameral bone cysts in the upper limb are at greater risk of fracture. J Orthop Surg (Hong Kong) 2009;17(02):157-160

3 Yilmaz G, Aksoy MC, Alanay A, Yazici M, Alpaslan AM. [Treatment of simple bone cysts with methylprednisolone acetate in children]. Acta Orthop Traumatol Turc 2005;39(05):411415

4 Öztürk R, Arıkan ŞM, Bulut EK, Kekeç AF, Çelebi F, Güngör BŞ. Distribution and evaluation of bone and soft tissue tumors operated in a tertiary care center. Acta Orthop Traumatol Turc 2019;53(03):189-194

5 Elmadağ M, Ceylan HH, Erdil M, Bilsel K. Apophyseal avulsion fracture of the anterior inferior iliac spine due to a simple bone cyst. Acta Orthop Traumatol Turc 2015;49(02):213-216

6 Singh S, Dhammi IK, Arora A, Kumar S. Unusually large solitary unicameral bone cyst: case report. J Orthop Sci 2003;8(04): 599-601

7 Jain SK, Nathan SS. An unusual presentation of a simple bone cyst in the scapula. Musculoskelet Surg 2012;96(03):227-231

8 Atalay İB, Yapar A, Öztürk R. Primary aneurysmal bone cyst of the scapula in adult patient: two case reports and a review of the literature. [published online ahead of print, 2019 Dec 20] Arch Orthop Trauma Surg 2019. Doi: 10.1007/s00402-01903327-z

9 Öztürk R, Arıkan ŞM, Toğral G, Güngör BŞ. Malignant tumors of the shoulder girdle: Surgical and functional outcomes. J Orthop Surg 
(Hong Kong) 2019;27(02):2309499019838355. Doi: 10.1177/ 2309499019838355

10 Erol B, Onay T, Çalışkan E, Aydemir AN, Topkar OM. Treatment of pathological fractures due to simple bone cysts by extended curettage grafting and intramedullary decompression. Acta Orthop Traumatol Turc 2015;49(03):288-296

11 Gündeş H, Şahin M, Alici T. Unicameral bone cyst of the lunate in an adult: case report. J Orthop Surg Res 2010;5(05):79

12 Mavrogenis AF, Rossi G, Rimondi E, Ruggieri P. Aneurysmal bone cyst of the acromion treated by selective arterial embolization. J Pediatr Orthop B 2011;20(05):354-358
13 Sherwani RK, Zaheer S, Sabir AB, Goel S. Giant cell tumor along with secondary aneurysmal bone cyst of scapula: A rare presentation. Int J Shoulder Surg 2008;2(03):59-61

14 Arıkan M, Toğral G, Yıldırım A, Irkkan Ç. A rare case of chondroblastoma of the acromion. Acta Orthop Traumatol Turc 2016;50 (06):691-693

15 Mahajan A, John B, John MJ. Acromion tumour as the primary presentation of multiple myeloma: case report. Int J Basic Appl Sci 2014;3(02):134-136 